\title{
Cobb-Douglas, Translog Stochastic Production Function and Data Envelopment Analysis in Total Factor Productivity in Brazilian Agribusiness
}

\author{
Paulo Dutra Constantin \\ Universidade Presbiteriana Mackenzie \\ pdcostantin@mackenzie.com.br
}

Diogenes Leiva Martin

Universidade Presbiteriana Mackenzie diomartin@mackenzie.com.br

\section{Edward Bernard Bastiaan de Rivera Y Rivera \\ Universidade Presbiteriana Mackenzie \\ edwber@mackenzista.com.br; riverarivera@uol.com.br}

\begin{abstract}
The objective of this paper is to apply a Cobb-Douglas, Translog Stochastic Production Function and Data Envelopment Analysis in order to estimate inefficiencies over time as well as respective TFP (Total Factor Productivity) sources for main Brazilian grain crops - namely, rice, beans, maize, soybeans and wheat - throughout the most recent data available comprising the period 2001-2006. The results indicate that, although positive changes exist in TFP for the sample analyzed, a decline in the use of technology has been evidenced for all grain crops in which it is observed a historical downfall in the use of inputs in Brazilian agriculture.
\end{abstract}

KEYWORDS: Total Factor Productivity, Stochastic Frontier, Data Envelopment Analysis.

\section{INTRODUCTION}

"Not all producers are technically efficient". As opposed to conventional microeconomic theory, such statement implies that not all producers are able to utilize the minimum quantity of required inputs in order to produce the desired quantity of output given the available technology. Similarly, not all producers are able to minimize necessary costs for the intended production of outputs.

From a theoretical point of view, producers do not always optimize their production functions. The production frontier characterizes the minimum number of necessary combinations of inputs for the production of diverse products, or the maximum output with various input combinations and a given technology. Producers operating above the production frontier are considered technically efficient, while those who operate under the production frontier are denoted technically inefficient.
The Stochastic Frontier Analysis - SFA is an analytical approach that utilizes econometric (parametric) techniques whose models of production recognize technical inefficiency and the fact that random shocks beyond producers' control may affect the product. Differently from non-parametric approaches that assume deterministic frontiers, SFA allows for deviations from the frontier, whose error can be decomposed for adequate distinction between technical efficiency and random shocks (e.g. labor or capital performance variations).

By the application of non-parametric methods as Data Envelopment Analysis - DEA, the Malmquist index is calculated by distance functions obtained by mathematical programming and allows for the absence of price information, utilizing physical quantities of multiple inputs and products instead. The main two components of the underlying index are technical change (innovation) and efficiency change ("catching up" effect towards the frontier). 
The objective of this paper is to apply the Stochastic Frontier Analysis technique in order to estimate increase or decrease in inefficiencies through time, as well as the linear programming method Data Envelopment Analysis, namely the Malmquist index, for the analysis of change in TFP (Total Factor Productivity) in main Brazilian grain crops - rice, beans, maize, soybeans and wheat - throughout the 20012006 period.

Among observed results, even though there have been positive changes in main Brazilian grain crops, there have been a decline in the component referring to technological innovations for all Brazilian grain crops analyzed between the 2005/2006 period in which it is observed a general downfall in input usage in agriculture.

\section{THEORETICAL FRAMEWORK}

\subsection{Stochastic Frontier Analysis - SFA}

In the presence of inefficiencies, the Stochastic Frontier Analysis - SFA emerges as a theoretical and practical framework, whose objective is to contribute for the definition and estimation of production frontiers. SFA has been developed from remote influences but the literature that directly influenced the development of SFA has been the theoretical framework about production efficiency beginning in the decade of 1950 by Koopmans (1951), Debreu (1951) and Shephard (1953). Farrell (1957) was the first to measure production efficiency empirically. The use of linear programming by Farrell influenced research by Boles (1966), Bressler (1966), Seitz (1966) and Sitorus (1966) and eventually the development of Data Envelopment Analysis (DEA) by Charnes, Coopers and Rhodes (1978). The influence from Farrell is also definite for the works by Aigner and Chu (1968), Seitz (1971), Timmer (1971), Afriat (1972) and Richmond (1974) - direct collaborators for the SFA development.

This parametric method of stochastic frontier considers production frontier as a random shock. Differently from a non-parametric method such as DEA that assumes a deterministic frontier, the stochastic frontier allows for deviations from the frontier to represent both inefficiency and an inevitable statistic noise which intends to be a closer approach to reality given that observations normally involve a random walk.

SFA has its origins in two papers: Aigner, Lovell and Schmidt (1977) and Meeusen e van den Broeck
(1977), followed by the works by Battese and Corra (1977). These three original works represent, in the context of production frontier, the error term defined in a structurally composed manner. Since then, the SFA has been developed by several collaborators: Schmidt and Lovell (1979), Jondrow et al. (1982), Greene (1980), Stevenson (1980), Lee (1983), Koop and Diewert (1982), Pitt and Lee (1981), Schmidt and Sickles (1984), Cornwell, Schmidt and Sickles (1990), Kumbhakar (1990), Battese and Coelli (1992), among other researchers.

The models of stochastic production frontier address technical efficiency and recognize the fact that random shocks beyond the control of producers may affect the production output. Therefore, in these models, the impact of random shocks (as labor or capital performance) on the product can be separated from the impact of technical efficiency variation. These models were simultaneously introduced by Aigner, Lovell and Schmidt (1977) and Meeusen and van den Broeck (1977).

This paper has followed the dominant functional specification in literature based on the works by Bettese and Coelli $(1992,1995)$, in which it is formalized technical inefficiency in the production function of stochastic frontier for panel data. Thus, consider the following production function of a given state $i$ :

$$
y_{i t}=\exp \left(x_{i t} \beta+v_{i t}-u_{i t}\right)=\exp \left(x_{i t} \beta+v_{i t}\right) \exp \left(-u_{i t}\right)
$$

or

$\ln y_{i t}=x_{i t} \beta_{i t}+v_{i t}-\mu_{i t}$

$i=1,2,3, \ldots, n i=1,2,3, \ldots, n \quad$ sectors and $t=1,2,3, \ldots, T t=1,2,3, \ldots, T$ years

where $y_{i t}$ is the vector representing produced quantities by the unit of production $i i$ in period $t t ; x_{i t}$ $x_{i t}$ is the vector of inputs used by the unit of production in period $t t ; \beta \beta$ is the vector of coefficients to be used that define the production technology.

The terms $v v$ and $u u$ are vectors representing distinct error components. The first term refers to the random part of error, with normal distribution, independent and identically distributed (iid), truncated in zero and variance $\sigma_{v}^{2} \sigma_{v}^{2}\left[v \sim \mathrm{iid} \mathrm{N}\left(0, \sigma_{v}^{2} \sigma_{v}^{2}\right)\right]$. The second term concerns the part relating to technical inefficiency, constituting a deviation in relation to the production frontier (which can be inferred by negative sign and by 
restriction $u \geq \mathbf{0} u \geq \mathbf{0}$ ). They are nonnegative random variables with normal truncated distribution, that is, non-null $\mu \mu$ mean $\left[u \sim \mathrm{N}^{+}\left(\mathrm{m}, \mathrm{s}_{u}^{2}\right)\right]$.

The OLS (Ordinary Least Squares) method provides a simple test for the identification of the presence of technical inefficiency in data. If $u_{i}=\mathbf{0} u_{i}=\mathbf{0}$, then $\varepsilon_{i}=\mathbf{0} \quad \varepsilon_{i}=\mathbf{0}$. Thus, the error term is symmetric and data do not evidence technical inefficiency. However, if $u_{i}>\mathbf{0} u_{i}>\mathbf{0}$, then the distribution of $\varepsilon_{i}=v_{i}-u_{i} \varepsilon_{i}=v_{i}-u_{i}$ is negatively symmetric and evidences of technical inefficiency in data exist. Thus, the term $\mu_{i t} \mu_{i t}$ quantifies technical inefficiency or the distance in relation to the efficiency frontier. The most efficient estimate presents value 0 for $\mu_{i t}$ $\mu_{i t}$. This suggests that the presence of technical inefficiency can be tested directly by the residuals of OLS.

Consider technical inefficiency as time-variant

$\mu_{i t}=[\exp (-\eta(t-T))] \mu_{i}$

When $\eta \eta$ is positive, the value inside the brackets of the exponential term will become non-negative and ( $\left.\exp (-\eta(t-T))] \mu_{1} i \exp (-\eta(t-T))\right] \mu_{1} i$ will not be smaller than unity. This is the case in which $\mu_{i t} \geq \mu_{i}$ $\mu_{i t} \geq \mu_{i}$. In other words, technical inefficiency will have decreasing effects through time (positive effect in technical efficiency over time). In case $\eta \eta$ is negative, inefficiency will be increasing through time (also defined as persistent inefficieRiverancy).

\subsection{Data Envelopment Analysis - DEA}

A productively efficient firm is the one not able to increase its production unless some of its inputs are also increased. By the Malmquist index, such firm achieves an efficiency score of 1 . Similarly, a productively inefficient firm obtains an efficiency punctuation smaller than 1.

Introduced by Caves et al. (1982) in its empirical usage, the Malmquist index do not require costs or income, being capable of measuring increase in TFP in a scenario of multiple products. For the Malmquist index definition, we assume that for each period of time, $t=1, \ldots, T t=1, \ldots, T$ production technology $S^{t} S^{t}$ models the transformation of inputs $x^{t} \in \boldsymbol{\Re}_{+}^{n}$ $x^{t} \in \boldsymbol{\Re}_{+}^{n}$ into products $y^{t} \in \boldsymbol{\Re}_{+}^{m} y^{t} \in \boldsymbol{\Re}_{+}^{m}$.

(3) $S^{t}=\left\{\left(x^{t}, y^{t}\right): x^{t}\right.$ produces $\left.y^{t}\right\}$

$S^{t}=\left\{\left(x^{t}, y^{t}\right): x^{t}\right.$ produces $\left.y^{t}\right\}$
Färe et al. (1994) define the output distance function at time $t$ as

$$
D_{0}^{1}\left(x^{t}, y^{t}\right) D_{0}^{1}\left(x^{t}, y^{t}\right)
$$

Thus, the distance function in relation to two different periods measure the maximum proportional change required in production to turn $\left(x^{t-1}, y^{t-1}\right)$ $\left(x^{t-1}, y^{t-1}\right)$ feasible in relation to technology in period $t t$. Caves, Christensen e Diewert (CCD) (1982) define Malmquist productivity as

$$
M_{C C D}^{t}=\frac{D_{0}^{t}\left(x^{t+1}, y^{t+1}\right)}{D_{0}^{t}\left(x^{t}, y^{t}\right)}
$$

$M_{C C D}^{t}=\frac{D_{0}^{t}\left(x^{t+1}, y^{t+1}\right)}{D_{0}^{t}\left(x^{t}, y^{t}\right)}$

In this formulation, technology at time $t$ is the reference technology. Alternatively, Färe et al. (1994) define a Malmquist index based on period $(t+1)$ $(t+1)$ as

$$
M_{C C D}^{t+1}=\frac{D_{0}^{t+1}\left(x^{t+1}, y^{t+1}\right)}{D_{0}^{t+1}\left(x^{t}, y^{t}\right)}
$$

$M_{C C D}^{t+1}=\frac{D_{0}^{t+1}\left(x^{t+1}, y^{t+1}\right)}{D_{0}^{t+1}\left(x^{t}, y^{t}\right)}$

In order to avoid an arbitrary benchmark, Färe et al. (1994) specify the Malmquist index for changes in productivity as the geometric mean of both CCD type Malmquist indexes:

$$
\begin{aligned}
& M_{0}\left(x^{t+1}, y^{t+1}, x^{t}, y^{t}\right)=\left[\left(\frac{D_{0}^{t}\left(x^{t+1}, y^{t+1}\right)}{D_{0}^{t}\left(x^{t}, y^{t}\right)}\right)\left(\frac{D_{0}^{t+1}\left(x^{t+1}, y^{t+1}\right)}{D_{0}^{t+1}\left(x^{t}, y^{t}\right)}\right)\right]^{\frac{1}{2}} \\
& M_{0}\left(x^{t+1}, y^{t+1}, x^{t}, y^{t}\right)=\left[\left(\frac{D_{0}^{t}\left(x^{t+1}, y^{t+1}\right)}{D_{0}^{t}\left(x^{t}, y^{t}\right)}\right)\left(\frac{D_{0}^{t+1}\left(x^{t+1}, y^{t+1}\right)}{D_{0}^{t+1}\left(x^{t}, y^{t}\right)}\right)\right]^{\frac{1}{2}}
\end{aligned}
$$

An equivalent form to express this index:

(8)

$$
\begin{aligned}
& M_{0}\left(x^{t-1}, y^{t+1}, x^{t}, y^{t}\right)=\frac{D_{0}^{t+1}\left(x^{t+1}, y^{t+1}\right)}{D_{0}^{t}\left(x^{t}, y^{t}\right)}\left[\left(\frac{D_{0}^{t}\left(x^{t+1}, y^{t+1}\right)}{D_{0}^{t+1}\left(x^{t+1}, y^{t+1}\right)}\right)\left[\frac{D_{0}^{t}\left(x^{t}, y^{t}\right)}{D_{0}^{t+1}\left(x^{t}, y^{t}\right)}\right]\right]^{\frac{1}{2}} \\
& M_{0}\left(x^{t-1}, y^{t+1}, x^{t}, y^{t}\right)=\frac{D_{0}^{t+1}\left(x^{t+1}, y^{t+1}\right)}{D_{0}^{t}\left(x^{t}, y^{t}\right)}\left[\left(\frac{D_{t}^{t}\left(x^{t+1}, y^{t+1}\right)}{D_{0}^{t+1}\left(x^{t+1}, y^{t+1}\right)}\right)\left[\frac{D_{0}^{t}\left(x^{t}, y^{t}\right)}{D_{0}^{t+1}\left(x^{t}, y^{t}\right)}\right]\right]^{\frac{1}{2}}
\end{aligned}
$$

In the study concerning industrialized countries, Färe et al. (1994) observe that this decomposition allows for a measure in which one distinction exists between technical efficiency components ("catchingup") and technology change (innovation), given that previous works did not distinguish between these 
two components.

The ratios inside the brackets measure changes in technology dislocations to input levels $x^{t} x^{t}$ and $x^{t+1} x^{t+1}$ , respectively. Thus, changes in technology is measured as the geometric mean of these two components. The terms out of the brackets measure technical efficiency relative to $t t$ and $t+\mathbf{1} t+\mathbf{1}$, capturing changes in efficiency over time, that is, whether production becomes closer (catching up effect) or more distant from the frontier.

Observe that if $x^{t}=x^{t-1} x^{t}=x^{t-1}$ and $y^{t}=y^{t-1}$ $y^{t}=y^{t-1}$ (i.e., no input and product change between periods), the productivity index do not signalize any change: $M_{0}()=.1 M_{0}(\cdot)=1$. Improvements in productivity result in Malmquist indexes greater than unity. Similarly, performance deterioration over time is associated with a Malmquist index smaller than unity. Besides, improvements in any of the Malmquist index components are also associated with values greater than unity of these components; and deterioration is associated with values smaller than unity.

Finally, Färe et al. (1994) highlight that, while the product of the components of efficiency change and technical change must, by definition, equal the Malmquist index, these components may be moving in opposite directions. For instance, a Malmquist index greater than unity, say 1.25 (which signalizes productivity gain), could have a component of efficiency change smaller than 1 (e.g. 0.5) and a change in technology component greater than unity (e.g., 2,5).

Alternatively, Alam (2001) expresses the Malmquist index in terms of distances throughout the y-axis, based on Figure 1:

Figure 1: Malmquist Index

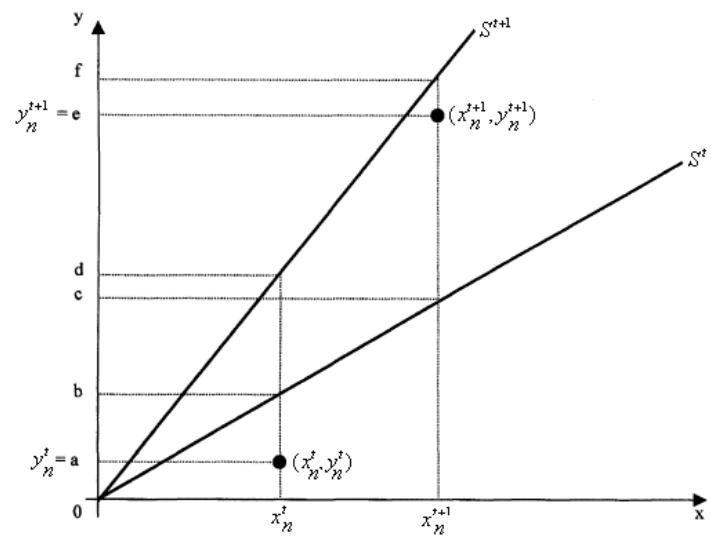

Source: Adapted by the authors from Alam (2001).
Malmquist Index $=\frac{(O e / O f)}{(O a / O b)} *\left[\frac{(O c / O c}{\left(\frac{O e}{O f}\right)} \frac{(O a / O b)}{\left(\frac{O a}{O d}\right)}\right]^{\frac{1}{2}}$

$=\left(\frac{O e}{O f}\right)\left(\frac{O b}{O a}\right) *\left[\left(\frac{O f}{O c}\right)\left(\frac{O d}{O b}\right)\right]^{\frac{1}{2}}=E_{t+1} * A_{t+1}$
$=\left(\frac{O e}{O f}\right)\left(\frac{O b}{O a}\right) *\left[\left(\frac{O f}{O c}\right)\left(\frac{O d}{O b}\right)\right]^{\frac{1}{2}}=E_{t+1} * A_{t+1}$

Consider the case of a firm $n n$ in period $t t$ represented by $\left(x_{n}^{t}, y_{n}^{t}\right)\left(x_{n}^{t}, y_{n}^{t}\right)$. Given that it is located under $S_{t} S_{t}$, this firm is not efficient and its productive inefficiency is measured by the ratio $\mathrm{OaOa}$

$\overline{\mathrm{Ob}} \overline{\mathrm{Ob}}$. Similarly, the same firm in $t+1$, denoted by $\left(x_{n}^{t+1}, y_{n}^{t+1}\right)\left(x_{n}^{t+1}, y_{n}^{t+1}\right)$ is efficient in relation to the frontier $S^{t+1} S^{t+1}$ and its inefficiency measure $0 e 0 e$

is given by $\overline{0 f} \overline{0 f}$.

Given that this index captures the productivity dynamics by the incorporation of data from two different adjacent periods, $E_{t+1} E_{t+1}$ reflects change in relative efficiency, while $A_{t+1} A_{t+1}$ reflects changes in technology between periods $t t$ and $t+\mathbf{1} t+\mathbf{1}$. As for the index and its components, values smaller than 1 indicate a decline in productivity (regression), while values greater than 1 indicate growth (progress). For the firm $n n$ in the example, both components exceed 1. In terms of technical efficiency, the firm moved to a point closer to the contemporary relevant frontier, indicating that the production for this firm is converging to the frontier. In terms of technological change, the frontier, measured at levels $x x$ of inputs $x^{t} x^{t}$ and $x^{t+1} x^{t+1}$, moved between periods $t t$ and $t+\mathbf{1} t+\mathbf{1}\left(A_{1}(t+1)>1\right)$ $\left.A_{1}(t+1)>1\right)$ (ALAM, 2001).

\section{METHODOLOGY}

From LSPA (Systematic Survey of Agricultural Production) of January 2007 released by the Brazilian Institute of Geography and Statistics (IBGE), data has been gathered for the main Brazilian grain crops - rice, beans, maize and wheat. Thus, obtained productions have been analyzed for each culture (outputs), as well as harvested area in acres for each crop (inputs) annually. 
Additionally, from PAM (Municipal Agriculture Production) and the statistics available at the Ministry of Agriculture, data has been gathered on total quantity (in ton.) produced, harvested area (acres), agricultural credit (in Brazilian Real) and agricultural limestone (in ton.) for the period 2001 to 2006 for the 26 States of the Federation and the Federal District, allowing for the creation of regional dummies for the comparative analysis of total factor productivity.

Initially, data has been analyzed based on the stochastic frontier theory in order to verify gains or losses in efficiencies over time, expressed by the component $\eta \eta$ and the estimated parameters of variables that explain technical inefficiency. Considering technical inefficiency $\mu_{i t}=[\exp (-\eta(t-T))] \mu_{i} \mu_{i t}=[\exp (-\eta(t-T))] \mu_{i}$ as varying through time, if $\eta \eta$ is positive, the value inside the brackets of the exponential term will become nonnegative and $\exp (-\eta(t-T)) \exp (-\eta(t-T))$ will not be greater than 1 . This is the case in which $\mu_{i t} \geq \mu_{i}$ $\mu_{i t} \geq \mu_{i}$. In other words, technical inefficiency will be decreasing over time (positive effect of technical efficiency through time). If $\eta \eta$ is negative, inefficiency will be increasing. In case $\eta \eta$ is null, it is observed technical inefficiency that does not vary over time (also referred as persistent inefficiency).

In relation to Data Envelopment Analysis and the Malmquist index, Färe et al. (1994) discuss the usage of the VRS approach in the Malmquist index calculation. By calculating "change in efficiency" in relation to the VRS frontier, it is obtained the denominated "change in efficiency" and measured changes in production scale by the ratio between "change in efficiency" and "change in pure efficiency". Thus, the component change in efficiency (or technical efficiency) calculated in relation to technology with CRS can be decomposed in a component of change in pure efficiency (PEC, calculated in relation to the technology with VRS) and, in a component of change of scale efficiency (SEC), which represents changes in deviations between the CRS and VRS technologies.

Thus,

$M_{0}\left(y_{t+1}, x_{t+1}, y_{t}, x_{t}\right)=$ Technical Change $(T E C H) *$ Change in Pure Efficiency $(P E C) *$ Change in Sca

where

\section{Efficiency Change $(E F C H)=$ Change in Pure Efficiency $(P E C) *$ Change in Scale $(S E C)$}

which can be re-written in the following form:

Growth in TFP $=$ Efficiency Change $(E F C H) *$ Technical Change $(T E C H)$

The decomposition of Malmquist index assists in the determination of efficiency or inefficiency sources in a firm. $T E C H>1 T E C H>1$ indicates technical progress. $E F C H>1 E F C H>1$ means the firm is approximating towards optimal scale in $t+\mathbf{1} t+\mathbf{1}$.

\section{RESULTS AND DISCUSSION}

\subsection{Stochastic Frontier Analysis for Brazilian Agriculture: Cobb-Douglas Production Function}

The results related to the estimation of the stochastic frontier analysis according to a Cobb-Douglas production function is presented in Table 1. In the case of a Cobb-Douglas model, the significant variables were harvested area, agriculture credit and limestone - all assuming expected signs. The LR (Likelihood Ratio) statistic, which is a chi-square ( $\left.\chi^{\uparrow} 2\right) \chi^{\uparrow} 2$ ) distribution under the null hypothesis that there has not been effects of technical efficiency, presents significant value to the $1 \%$ level, indicating effects of technical inefficiency in the model.
The greatest elasticity observed is that of harvested area. This indicates the intense relationship that exists between production and harvested area, independently of the utilization of other factors that, ceteris paribus, would contribute for productivity. The credit variable reveals the second major elasticity, confirming the importance of agriculture credit to cover costs and particularly, to execute investments which responds for the greatest share of the data analyzed. As expected, assuming positive and inferior elasticity in relation to the other relevant factors, 
limestone contributes for productivity by correcting sole acidity, which assumes a maximizing role for the potential of productivity already established by the other factors.

The estimate of parameter $\gamma \gamma$, which measures the variability of the two sources of error (white noise disturbance and unilateral error), reached the level of 0.9469 . This result means that about $95 \%$ of total variance of composed error of the production function is explained by the variance of the technical inefficiency term. This represents the importance of incorporating technical inefficiency in production function.

The term relative to technical inefficiency assumes a temporal pattern of behavior represented by the $\boldsymbol{\eta} \boldsymbol{\eta}$ sign. In case this term is positive (negative), technical inefficiency will be decreasing (increasing) in time. If it assumes a null value, it is considered that technical inefficiency does not vary in time - also called persistent inefficiency. In the analysis, the term assumes negative value, which indicates that technical inefficiency in Brazilian agriculture, though not predominant, is increasing in time from 2000 to 2005.

Thus, the punctual reduction of inefficiency, which includes the concession of costs credit for income maintenance against fluctuations in prices and exchange rates, as well as investment credit for capital acquisition such as tractors and harvesters will certainly avoid the persistence of increasing inefficiency path in Brazilian agricultural productivity.

\section{Table 1 - Cobb-Douglas Production Function}

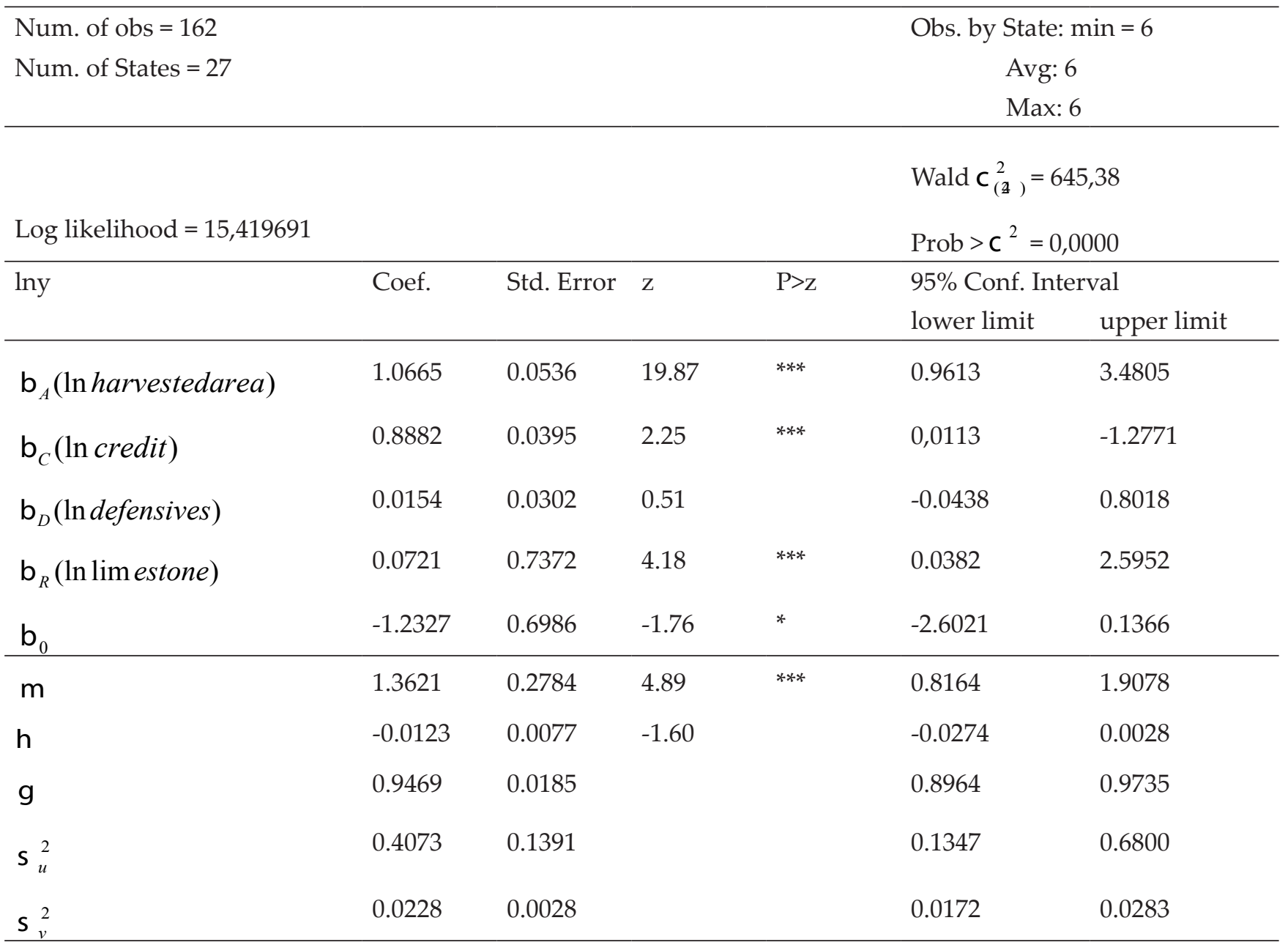

Source: Research results obtained from gathered PAM and Ministry of Agriculture data for the proposed stochastic frontier model.

Note: ${ }^{* * *}$ significant to the $1 \%$ level; ${ }^{* *}$ significant to the $5 \%$ level; ${ }^{*}$ significant to the $10 \%$ level. 


\subsection{Stochastic Frontier Analysis for Brazilian Agri- culture: Translog Production Function}

Assuming a logarithmic transcendental (translog) technology, the parameters estimates of the production frontier and the technical inefficiency component are presented in Table 2 . The statistically significant parameters at the level of $5 \%$ are essentially related to harvested area and agricultural credit, as well as the measures of regional technical inefficiency expressed by dummy variables. The LR (Likelihood Ratio) statistic presents significant value at $1 \%$ level, indicating effects of technical inefficiency in the model.

Analyzing the sample on the basis of stochastic frontier theory for the verification of gains or losses of efficiencies through time, it is observed that the $\eta \eta$ component assumes negative sign and is significant at $5 \%$ level. Thus, technical inefficiency is increasing over time for the analyzed sample. It is important to emphasize that $\eta \eta$ is unique for the analyzed sample. Thus, this component does not reveal productivity specificities for each state.

The coefficient for the mean of the error component relative to inefficiency, $\mu \mu$, is not statistically significant, indicating that the semi-normal distribution is more appropriate in relation to the normal truncated distribution $(\mu=\mathbf{0} \mu=\mathbf{0})$.
The positive sign of parameter $\beta_{t} \beta_{t}$ indicates that the occurrence of technical progress. The indicator of technical inefficiency, $\gamma \gamma$, presents approximated value of 0,90 . This result indicates that $90 \%$ of total composed error variance of the production function is explained by the variance of the technical inefficiency term. This reveals the importance to incorporate technical inefficiency in the production function.

In relation to the dummy variables parameters, they are all statistically significant to the $5 \%$ level. By having the Northeast region as reference for presenting a larger number of observations, it is verified that all the other regions are technically less efficient in relation to the reference region. Thus, by classifying according to the degree of increasing inefficiency, North region is followed by Southeast region, South and Center-West, respectively.

The coefficients $\beta_{t} \beta_{t}$ and $\beta_{t t} \beta_{t t}$ indicate that the neutral part of technical progress has a positive effect over production. The signs of the coefficients $\beta_{A t} \beta_{A t}$ , $\beta_{C t} \beta_{C t}, \beta_{D t} \beta_{D t}$ and $\beta_{R t} \beta_{R t}$ indicate, respectively, that the non neutral part of technical progress moves inversely with area, credit, defensives and accordingly with limestone. However, these parameters are not significant at the $5 \%$ level. That is, technical progress tends to diminish the usage of harvested area, agricultural credit, defensives and, on the other hand, is associated with the increase of limestone utilization.

Table 2 - Time-Varying Inefficiency Model (B\&C, 1992)

\begin{tabular}{|c|c|c|c|c|c|c|}
\hline Num. of obs $=162$ & & & & & \multicolumn{2}{|c|}{ Obs. by State: $\min =6$} \\
\hline Num. of States $=27$ & & & & & \multicolumn{2}{|c|}{ Avg: 6} \\
\hline & & & & & \multicolumn{2}{|c|}{ Max: 6} \\
\hline & & & & & \multicolumn{2}{|c|}{ Wald $C_{(y)}^{2}=3638,03$} \\
\hline Log likelihood $=46,578465$ & & & & & \multicolumn{2}{|c|}{ Prob $>c^{2}=0,0000$} \\
\hline $\ln y$ & Coef. & Std. Error & $\mathrm{z}$ & $\mathrm{P}>\mathrm{Z}$ & \multicolumn{2}{|c|}{ 95\% Conf. Interval } \\
\hline & & & & & lower limit & upper limit \\
\hline $\mathrm{b}_{t}(t)$ & 0,5324 & 0,2963 & 1,80 & * & $-0,0483$ & 1,1131 \\
\hline $\mathrm{b}_{t t}(1 / 2) t^{2}$ & 0,0094 & 0,0175 & 0,53 & & $-0,0250$ & 0,0437 \\
\hline $\mathrm{b}_{A}(\ln$ harvestedarea $)$ & 1,9117 & 1,8004 & 2,39 & $* * *$ & 0,3428 & 3,4805 \\
\hline $\mathrm{b}_{C}(\ln$ credit $)$ & $-2,6287$ & 0,6895 & $-3,81$ & $* * *$ & $-3,9801$ & $-1,2771$ \\
\hline $\mathrm{b}_{D}(\ln$ defensives $)$ & 0,0022 & 0,4079 & 0,01 & & $-0,7974$ & 0,8018 \\
\hline
\end{tabular}




\begin{tabular}{|c|c|c|c|c|c|c|}
\hline $\mathrm{b}_{R}(\ln \lim$ estone $)$ & 1,1503 & 0,7372 & 1,56 & & $-0,2945$ & 2,5952 \\
\hline $\left.\mathrm{b}_{A I}(1 / 2) \mathrm{b}_{A} \mathrm{~b}_{A}\right)$ & $-0,3438$ & 0,0810 & $-4,24$ & $* * *$ & $-0,5025$ & $-0,1849$ \\
\hline $\left.\mathrm{b}_{c}(1 / 2) \mathrm{b}_{C} \mathrm{~b}_{C}\right)$ & 0,1024 & 0,0583 & 1,76 & $* *$ & $-0,0118$ & 0,2167 \\
\hline $\left.\mathrm{b}_{\mathbb{D}}(1 / 2) \mathrm{b}_{D} \mathrm{~b}_{D}\right)$ & $-0,0006$ & 0,0323 & $-0,39$ & & $-0,0759$ & 0,0507 \\
\hline $\left.\mathrm{b}_{\mathbb{R}}(1 / 2) \mathrm{b}_{R} \mathrm{~b}_{R}\right)$ & $-0,0658$ & 0,0693 & $-0,95$ & & $-0,2017$ & 0,0702 \\
\hline $\mathrm{b}_{A}\left(t \mathrm{~b}_{A}\right)$ & $-0,0149$ & 0,0231 & $-0,64$ & & $-0,0602$ & 0,0304 \\
\hline $\mathrm{b}_{\mathbb{C}}\left(t \mathrm{~b}_{C}\right)$ & $\mid-0,0193$ & 0,0200 & $-0,97$ & & $-0,0585$ & 0,0198 \\
\hline $\mathrm{b}_{D}\left(t \mathrm{~b}_{D}\right)$ & $-0,0006$ & 0,0097 & $-0,06$ & & $-0,0196$ & 0,0185 \\
\hline $\mathrm{b}_{R}\left(t \mathrm{~b}_{R}\right)$ & 0,0189 & 0,0193 & 0,98 & & $-0,0190$ & 0,0568 \\
\hline $\mathrm{b}_{\mathbb{C}}$ & 0,1267 & 0,0577 & 2,19 & $* * *$ & 0,0134 & 0,2399 \\
\hline $\mathrm{b}_{D}$ & 0,0180 & 0,0425 & 0,42 & & $-0,0652$ & 0,1013 \\
\hline $\mathrm{b}_{\mathbb{R}}$ & 0,1189 & 0,0516 & 3,66 & $* * *$ & 0,0879 & 0,2903 \\
\hline$b_{0}$ & $-0,0029$ & 0,0239 & $-0,12$ & & $-0,0498$ & 0,0440 \\
\hline $\mathrm{b}_{\mathbb{R}}$ & $-0,1518$ & 0,0425 & $-3,56$ & $* * *$ & $-0,2352$ & $-0,0682$ \\
\hline$b_{B}$ & $-0,0351$ & 0,0413 & $-0,85$ & & $-0,1161$ & 0,0458 \\
\hline $\mathrm{d}_{1}$ (dummy North region) & 0,8565 & 0,1539 & 5,56 & $* * *$ & 0,5546 & 1,1582 \\
\hline $\begin{array}{l}d_{2} \text { (dummy Southeast } \\
\text { region) }\end{array}$ & 1,0735 & 0,2525 & 4,25 & $* * *$ & 0,5785 & 1,5684 \\
\hline $\mathrm{d}_{3}$ (dummy South region) & 1,1111 & 0,2599 & 4,27 & $* * *$ & 0,6016 & 1,6206 \\
\hline $\begin{array}{l}d_{4} \text { (dummy Center-West } \\
\text { region) }\end{array}$ & 1,2213 & 0,1893 & 6,45 & $* * *$ & 0,8503 & 1,5923 \\
\hline $\mathrm{b}_{0}$ & 15,1157 & 5,8720 & 2,57 & $* * *$ & 3,6067 & 26,6246 \\
\hline $\mathrm{m}$ & 0,9707 & 0,6959 & 1,39 & & $-0,3932$ & 2,3346 \\
\hline h & $-0,1290$ & 0,0395 & $-3,26$ & $* * *$ & $-0,2066$ & $-0,0514$ \\
\hline $\mathrm{hs}^{2}$ & $-1,7685$ & 0,4409 & $-4,01$ & $* * *$ & $-2,6327$ & $-0,9043$ \\
\hline ilgtg & 2,1697 & 0,5366 & 4,04 & $* * *$ & 1,1179 & 3,2215 \\
\hline$s^{2}$ & 0,1705 & 0,0752 & & & 0,0718 & 0,4048 \\
\hline g & 0,8974 & 0,0493 & & & 0,7536 & 0,9616 \\
\hline
\end{tabular}




\begin{tabular}{|l|l|l|l|l|l|l|}
\hline $\mathbf{S}_{u}^{2}$ & 0,1530 & 0,0756 & & & 0,0048 & 0,3013 \\
\hline $\mathbf{S}_{v}^{2}$ & 0,0174 & 0,0023 & & & 0,0129 & 0,0220 \\
\hline
\end{tabular}

Source: Research results obtained from gathered PAM and Ministry of Agriculture data for the proposed stochastic frontier model.

Note: ${ }^{* * *}$ significant to the $1 \%$ level; ${ }^{* *}$ significant to the $5 \%$ level; ${ }^{*}$ significant to the $10 \%$ level.

In Table 3 are presented the statistical tests applied in order to verify the consistency of specific hypothesis related to the production function frontier adopted in the empirical model.

Table 3 - Log Likelihood Test of Stochastic Production Frontier Parameters

\begin{tabular}{|c|c|c|c|c|}
\hline Test & Null Hypothesis & Value of $\mathrm{I}$ & Prob $>\mathrm{c}^{2}$ & $\begin{array}{c}\text { Decision } \\
(5 \% \text { level })\end{array}$ \\
\hline 1 & $H_{0}: \mathrm{b}_{t}=\mathrm{b}_{A}=\ldots=\mathrm{b}_{R}=\mathrm{b}_{\mathscr{A}}=\ldots=\mathrm{b}_{B}=0$ & 40.71 & 0.0000 & Reject $\mathrm{H}_{0}$ \\
\hline 2 & $H_{0}: \mathrm{d}_{1}=\mathrm{d}_{2}=\mathrm{d}_{3}=\mathrm{d}_{4}$ & 50.67 & 0.0000 & Reject $\mathrm{H}_{0}$ \\
\hline 3 & $H_{0}: t=t^{2}=t \mathrm{~b}_{A}=t \mathrm{~b}_{C}=t \mathrm{~b}_{D}=t \mathrm{~b}_{R}=0$ & 6.23 & 0.3984 & Accept $\mathrm{H}_{0}$ \\
\hline
\end{tabular}

Source: Research results obtained from gathered PAM and Ministry of Agriculture data for the proposed stochastic frontier model.

The first null hypothesis relates to the adequacy test of Cobb-Douglas model relative to the less restrictive functional form expressed by the translog. Thus, it is tested the hypothesis that all the second order coefficients and the cross products are equal to zero. The value of the log likelihood ratio, 40.71, is greater than the critical value of the statistic $\chi_{(11)}^{2} \chi_{(11)}^{2}$ with $5 \%$ significance level to the right.

Duffy and Papageorgiou (2000) reject the CobbDouglas specification utilizing a data panel for 82 countries in a period of 28 years. Additionally, by examining the impact of production technology over technical efficiency, Kneller and Stevens (2003) reject the specification of the aggregate production function over the efficiency measures. Thus, translog production function constitutes a more flexible firm and is an approximation for any production frontier. The result of this test is presented on Table 2 rejects the specification in the form of a Cobb-Douglas function in favor of the translog specified model.

The second analysis refers to the joint significance tests of the parameters of the variables that explain technical inefficiency. The result rejects the hypothesis that the parameters are simultaneously equal to zero.
The last test examines the stability of the production frontier in relation to the time variable, that constitutes the presence or not of technology progress in the analyzed period. Thus, the result of the test accepts the null hypothesis that there have not been any of the known forms for the sample and the analyzed period.

According to the data of the analyzed period, it is observed that an amelioration of aggregate productivity exists over time. In a decreasing order, the Brazilian regions that represent greater relative degree of efficiency were the Northeast, North, Southeast, South and Center-West regions. This result points to the new Brazilian agriculture frontiers where the production of grain crops advances rapidly, followed by livestock activity.

Additionally, the most significant inputs that have contributed to Brazilian agriculture productivity were land factor, as well as agriculture credit. On the other hand, the inputs related to agricultural defensives and limestone were not significant to explain Brazilian agriculture productivity throughout the analyzed period.

According to the Economic Bulletin by IPEA (Brazilian Institute of Applied Economic Research), consid- 
ering the agriculture years 2000/2001 to 2004/2005, the sector has increased its debt in $\mathrm{R} \$ 41,8$ billion solely due to investment credit, constituting half of the total agriculture credit. The investment credit differs for not having annual cycle as credit destined for covering costs destined to cover normal expenses of production cycles. It is cumulative and exerts significant importance in the analysis of behavior in the agriculture sector.

For illustration purposes, considering only the agriculture years 2003/2004 and 2004/2005, the sector has contracted additional debt of $\mathrm{R} \$ 20,9$ billion, only on investment rubric - almost the same value of credit for costs which was, on average, $\mathrm{R} \$ 22$ billion (B. CONJ. IPEA, 2005). Thus, agriculture credit inserted in the model is an adequate and relevant proxy for the representation of machinery in the contribution of productivity in Brazilian agriculture.

\subsection{Data Envelopment Analysis (DEA): Malmquist} Index

Utilizing data from LSPA/IBGE for the main grain crops in Brazilian agriculture - rice, beans, maize, soybeans and wheat - the following results have been obtained according to Table 5 .

Table 5 - Total Factor Productivity Means and its Components, Grain Crops, Brazil (2001-2006)

\begin{tabular}{|c|c|c|c|c|c|}
\hline Crop & $\begin{array}{c}\text { Malmquist } \\
\text { Index }\end{array}$ & $\begin{array}{c}\text { Technical } \\
\text { change } \\
(\mathrm{TECH})\end{array}$ & $\begin{array}{c}\text { Efficiency } \\
\text { change } \\
(\mathrm{EFCH})\end{array}$ & $\begin{array}{c}\text { Change } \\
\text { in Pure } \\
\text { Efficiency } \\
(\mathrm{PEC})\end{array}$ & $\begin{array}{c}\text { Change in } \\
\text { Scale (SEC) }\end{array}$ \\
\hline Rice & 1.152 & 1.270 & 0.907 & 0.930 & 0.975 \\
\hline Beans & 1.303 & 1.270 & 1.027 & 1.013 & 1.013 \\
\hline Maize & 1.300 & 1.270 & 1.024 & 1.020 & 1.004 \\
\hline Soy & 1.262 & 1.270 & 0.994 & 0.970 & 1.024 \\
\hline Wheat & 1.218 & 1.270 & 0.959 & 1.001 & 0.958 \\
\hline Mean & $\mathbf{1 . 2 4 6}$ & $\mathbf{1 . 2 7 0}$ & $\mathbf{0 . 9 8 1}$ & $\mathbf{0 . 9 8 6}$ & $\mathbf{0 . 9 9 5}$ \\
\hline
\end{tabular}

Source: Elaborated by the authors.

In the period from 2001 to 2006, PTF in main Brazilian grain crops increased $24.6 \%$ according to calculation of Malmquist indexes. The component of this growth was the technical change index, which increased $27 \%$. On the other hand, the component referring to efficiency change declined 1.9\% during the period. Thus, it is considered that the effect of technology innovation during the period in study has been more expressive than effect in efficiency change for the analyzed crops.

Among analyzed crops, beans were the culture that underwent the greatest increase in TFP $(+0.30 \%)$ during the observed period. In addition, it $5 \%$ is analyzed that the principal component of such TFP increase was technical change (+27), since growth in efficiency responded for only $2.7 \%$ of TFP elevation. Decomposing the EFCH index, it is verified that the indexes of pure efficiency change and scale change have responded for $50 \%$ of the underlying index increase, given the $1.3 \%$ growth for both.
Maize culture was the crop that obtained the second largest rise in TFP during the analyzed period. It is observed that its increase of $30 \%$ in the Malmquist index is predominantly due to technical change, which incurred an increase of $27 \%$, similarly to global mean of data in study. However, the component of technical efficiency did not suffer a regress, but a $2.4 \%$ increase. Among its subcomponents, the elevation of the EFCH index occurred mainly due to change in pure efficiency, which progressed $2 \%$, while the change in scale component suffered a $0.4 \%$ increase.

It is also observed that the soybeans culture suffered the third major increase in TFP $(+26,2 \%)$, in which index of technical change was predominant over change in efficiency. However, in contrast to the soybeans culture, there has been a regress in change in efficiency $(-0.6 \%)$. It is verified that such decline in this component occurs due to the regression of change in scale, which presented a 3\% decline, and not because of alterations in the component refer- 
ring to scale change, which obtained a $2.4 \%$ growth during the study period.

Additionally, the wheat crop obtained the 4th major elevation in TFP (+21.8) throughout the observed period, in which effects occurred exclusively by effects in technical change, in which technology innovation is implicit, which in turn obtained a $27 \%$ progress, corresponding to the mean of crops in study. However, there has been efficiency change for this culture throughout the analyzed period (-4.1\%). Among its components, the regression in this item occurred due to changes in scale, which suffered a decline of $4.2 \%$ during the years from 2001 to 2006 . In different circumstances, an amelioration or stability in this index would have been verified, since the component referring to change in pure efficiency for the wheat crop obtained a $0.01 \%$ progress.

It is observed that, among main Brazilian grain crops, the rice culture suffered the smallest growth in TFP between 2001 and $2006(+15.2 \%)$. Similarly to other crops, a progress in technical change $(+27 \%)$ is observed. However, the regress in the index related with change in efficiency was the most expressive between the analyzed grains $(-9.3 \%)$, being the unique culture to suffer a decrease in pure efficiency $(-7 \%)$ and change in scale $(2.5 \%)$.

Thus, all main Brazilian grain crops incurred in progress by the index referring to technical change. In other words, it is observed the dislocation of the technology frontier, once detected that, on average, the product of a crop at $\boldsymbol{t}+\mathbf{1} \boldsymbol{t}+\mathbf{1}$ is greater than the potential maximum product that could have been obtained at $\boldsymbol{t} \boldsymbol{t}$ in relation of production factors of $t+1 t+1$.

The component that negatively influenced in the Malmquist index performance verified in the cultures of rice, soybeans and wheat relates to change in efficiency. Given that this component of "change in efficiency", calculated in relation to CRS technology, can be decomposed in changes in "pure efficiency" and "changes in efficiency", it is observed that all crops experience regress either in "pure efficiency" only - change in efficiency in relation to the VRE frontier, as is the case of soybeans - or solely the regress in "scale change" - ratio between change in efficiency and change in pure efficiency, representing alterations in deviations between technologies CRS and VRE - as occurred with the wheat culture. However, exception is verified for rice culture in which both types of regress related to changes in efficiency occurred.

From Tables 6, 7 and 8, we verify the annual TFP evolution and its principal components - efficiency change (approximation to the frontier) and technical efficiency (innovation) - for each crop, analyzing changes particularly among the last studied periods (2005/2006).

Table 6 - Total Factor Productivity, Grain Crops, Brazil (2001-2006)

\begin{tabular}{cccccc}
\hline Year & Rice & Beans & Maize & Soy & Wheat \\
2002 & 0.719 & 1.113 & 1.327 & 1.310 & 1.297 \\
2003 & 1.538 & 1.194 & 4.057 & 2.720 & 3.498 \\
2004 & 2.407 & 1.802 & 0.644 & 1.235 & 0.987 \\
2005 & 1.445 & 1.504 & 1.153 & 0.878 & 0.757 \\
2006 & 0.526 & 1.045 & 0.929 & 0.830 & 0.790 \\
\hline
\end{tabular}

Source: Elaborated by the authors.

Table 7 - Efficiency Change, Grain Crops, Brazil (2001-2006)

\begin{tabular}{cccccc}
\hline Year & Rice & Beans & Maize & Soy & Wheat \\
2002 & 0.649 & 1.005 & 1.198 & 1.182 & 1.171 \\
2003 & 0.414 & 0.321 & 1.091 & 0.731 & 0.941 \\
2004 & 2.666 & 1.996 & 0.714 & 1.367 & 1.093 \\
2005 & 1.397 & 1.454 & 1.115 & 0.849 & 0.732 \\
2006 & 0.614 & 1.218 & 1.084 & 0.967 & 0.921 \\
\hline
\end{tabular}

Source: Elaborated by the authors.

Table 8 - Technical Change, Grain Crops, Brazil (2001-2006)

\begin{tabular}{cccccc}
\hline Year & Rice & Beans & Maize & Soy & Wheat \\
2002 & 1.108 & 1.108 & 1.108 & 1.108 & 1.108 \\
2003 & 3.719 & 3.719 & 3.719 & 3.719 & 3.719 \\
2004 & 0.903 & 0.903 & 0.903 & 0.903 & 0.903 \\
2005 & 1.034 & 1.034 & 1.034 & 1.034 & 1.034 \\
2006 & 0.858 & 0.858 & 0.858 & 0.858 & 0.858 \\
\hline
\end{tabular}

Source: Elaborated by the authors.

From the presented tables, it is observed that only the culture of beans increased in its TFP from 2005 to 2006. We analyze that efficiency changes surpassed 
the negative performance of the component related do innovation. On the other hand, maize culture was the sole crop besides beans that obtained an increase in the component related to change in efficiency. However, this progress did not compensate the decline suffered by the technical change index.

Thus, taking into account the hypothesis that firms mark-ups are positively related to productivity, the crops of rice, wheat, soy and beans incurred in the largest declines in mark-up in 2006 - mainly due to technological issues but also significantly affected by efficiency. For the last two periods, the largest and only mark-up increase is observed for beans. Following Sumanth (1985), since the productivity has grown at a larger velocity (in this case, due to efficiency change) than other crops, mark-up increase for beans has been favored due to lower costs that are not entirely transmitted to consumers.

A general decline in technological change certainly affected mark-ups negatively for all grain crops in Brazilian agriculture. Therefore, the manner in which farmers could maintain and increase their mark-ups has been either by exports, since higher mark-ups can be charged due to the presence of trade costs, or increase in efficiency that affects mark-ups to all markets. Assuming that commodity producers are essentially price takers, total factor productivity is the ultimate form of cost decrease and opportunity for greater mark-ups both domestically and abroad. However, in 2006 in particular, technology has not been able to function as a tool for cost decrease and mark-up increase in the agriculture of grain crops in Brazil.

Common evidence to all analyzed cultures is the decline in technology component in 2006 as consequence of agriculture crisis and its indebtedness which affected mainly grain crops, thus interfering in the acquisition of inputs such as machinery and fertilizers that would represent technology innovation captured by this component in Malmquist index for increase in productivity.

According to IPEA, the increase in indebtedness occurred because of two conditions satisfied: excessively optimistic expectations in relation to the future and a generous supply of credit given the underlying business risk. The optimistic expectations were on the basis of increase in commodities prices that coincided with exchange rate devaluation, seen as a permanent phenomenon with the end of anchor currency in 1999 and Chinese economic growth.
On the other hand, the expansion of agricultural frontier especially in the Center-West for the grain crops was covered by credit from private and public banking institutions, as well as by product supplier firms. The crop expansion was associated with a high indebtedness of producers in the short and long term, inducing the financial system to restrict industry's access to new borrowings, interfering in maintenance of the current level of activities and, therefore, reflecting on acquisition of new technologies for productivity increase (B. CONJ. IPEA., 2005, 2006, 2006a, 2007).

Nonetheless, even with government intervention by renegotiation of farmers' debts in 2006, accumulated debts continue to slow a new expansionary leap in activity that would be verified by positive technological indexes, depressing the potential capacity for growth and making new investments unfeasible both for the incorporation of new areas and for capital seeking productivity increase. Thus, the negative performance in 2006 in technology change for all cultures is evidenced by downfall in agriculture inputs usage such as fertilizers and limestone (B. CONJ. IPEA., 2005, 2006, 2006a, 2007).

\section{CONCLUSION}

In this paper, the technique of Stochastic Frontier Analysis has been applied for the estimation of increase or decrease in inefficiencies through time, as well as the linear programming method Data Envelopment Analysis and Malmquist index for the analysis of TFP sources for the Brazilian crops of beans, maize, soybeans, wheat and rice - considered the main grain crops in Brazil - throughout the period that comprehends the years from 2001 to 2006, the most recent data available.

According to the Cobb Douglas model, we verify that the greatest elasticity observed is that of harvested area, followed by credit variable, confirming the importance of agriculture credit to cover costs and, particularly, to execute investments which responds for the greatest share of the data analyzed. As expected, assuming positive and inferior elasticity in relation to the other relevant factors, limestone contributes for productivity by correcting sole acidity, which assumes a maximizing role for the potential of productivity already established by the other factors.

In the stochastic frontier analysis for the Brazilian agriculture, assuming a Translog technology, it is observed no increase in aggregate productivity 
throughout the analyzed period. In a decreasing order, the Brazilian regions presenting the highest relative degree of efficiency were the Northeast, North, Southeast and Center-West. This results points to the new Brazilian agricultural frontiers where grain crop production advances rapidly, followed by livestock activity.

Additionally, the most significant inputs that contributed for Brazilian agriculture productivity were land factor, as well as the agriculture credit - the latter being an adequate and relevant proxy for representation of machinery in the contribution for Brazilian agriculture productivity. On the other hand, the inputs related to agricultural defensives and limestone were not significant to explain Brazilian agriculture productivity throughout the observed period.

On the other hand, the Malmquist indexes revealed clarifying results for independent crop analysis. In relation to the means throughout the study period, it is observed that major TFP changes occurred, in a decreasing order, for the cultures of beans, maize, soybeans, wheat and rice. Although the mean variations have indicated positive TFP changes, when analyzing changes between the years of 2005 and 2006, it is verified a decline in the component representing technology innovations for all major Brazilian grain crops, jointly with the loss of productive efficiency for all cultures, excepting beans and maize.

Thus, taking into account the hypothesis that firms mark-ups are positively related to productivity, the crops of rice, wheat, soy and beans incurred in the largest declines in mark-up in 2006 - mainly due to technological issues but also significantly affected by efficiency. However, only the beans crop assumed positive variation in its TFP, since it was the only culture among principal Brazilian grain crops in which efficiency gain surpassed the negative effect of technology use. The generalized decline in the technology component can be explained by the indebtedness crisis in agriculture that affected particularly grain crops in 2005/2006, generating a downfall in the employment of agriculture inputs and interfering negatively in the maintenance of current level of agriculture activities in Brazil and, especially, as observed for the grain cultures analyzed.

\section{REFERENCES}

AFRIAT, S. N. Efficiency Estimation of Production Functions. International Economic Review, XI11, 568-98, 1972.
AIGNER, D.J.; CHU, S. F. Estimating the Industry Production Function. American Economic Review, 58, 826-39, 1968.

AIGNER, D.; LOVELL, C. A. K.; SCHMIDT, P. Formulation and Estimation of Stochastic Frontier Production Function Models. Journal of Econometrics, 6, 21-37, 1977.

ALAM, I. M. S. A Non-Parametric Approach for Assessing Productivity Dynamics of Large Banks. Journal of Money, Credit and Banking, 33, $121-139,2001$.

BATTESE, G.; COELLI, T. Frontier production functions, technical efficiency and panel data with application to paddy farmers in India. Journal of Productivity Analysis, v. 3, pp. 153-169, 1992.

BATTESE, G.; COELLI, T. A Model for Technical Inefficiency Effects in a Stochastic Frontier Production Function for Panel Data. Empirical Economics, v. 20, pp. 325-332, 1995.

BOLES, J. N. Efficiency Squared-Efficient Computation of Efficiency Indexes. Proc. Thirty-ninth Ann. Meeting, Western Farm Econ. Assoc., 1966.

BRESSLER, R. G. "The Measurement of Productive Efficiency. Proc. Thirty-ninth Ann. Meeting, Western Farm Econ. Assoc., 1966.

CAVES, D. W.; CHRISTENSEN, L. R.; DIEWERT, W. E. The Economic Theory of Index Numbers and the Measurement of Input, Output, and Productivity, Econometrica 50: 1393-1414, 1982.

CHARNES, A.; COOPER, W. W.; RHODES, E. Measuring the efficiency of decision making units. European Journal of Operational Research, v. 2, n. 6, p. 429-444, 1978.

COELLI, T. J.; RAO, D. S. P. Total Factor Productivity Growth in Agriculture: A Malmquist Index Analysis of 93 Countries, 1980-2000. Working Paper no. 02/2003, Centre for Efficiency and Productivity Analysis, School of Economics, The University of Queensland, 2003

CORNWELL, C.; SCHMIDT, P. SICKLES, R. Production Frontiers with Cross-Sectional and Time-Series Variation in Efficiency Levels. Journal of Econometrics 46, 185-200, 1990.

DEBREU, G. The coefficient of resource utilization. Econometrica, 19, p. 273-292, 1951.

DUFFY , J.; PAPAGEORGIOU, C. A cross-country empirical investigation of the aggregate production function specification. Journal of Economic Growth, 5, p. 87-120, 2000.

FARE, R.; GROSSKOPF, S.; NORRIS, M; ZHANG, Z. Productivity Growth, Technical Progress and Efficiency Changes in Industrialized Countries. American Economic Review, 84, 66-83, 1994.

FARRELL, M. J. The measurement of productive efficiency. Journal of the Royal Statistical Society, Series A, Part 3, p. 253-290, 1957.

GREENE, W. H. Maximum Likelihood Estimation of Econometric Frontier Functions. Journal of Econometrics, XI11, 27-56, 1980.

IBGE (Instituto Brasileiro de Geografia e Estatística). Levantamento Sistemático da Produção Agrícola. Rio de Janeiro, v.18, n.01, 
Constantin, P. D. Martin, L. M. Rivera, E. B. B. R.: Cobb-Douglas, Translog Stochastic Production Function and Data Envelopment...

p.1-76, jan.2007.

IPEA (Instituto de Pesquisa Econômica Aplicada). Boletim de Conjuntura, n. 71, dez. 2005.

IPEA (Instituto de Pesquisa Econômica Aplicada). Boletim de Conjuntura, n. 73, jun. 2006.

IPEA (Instituto de Pesquisa Econômica Aplicada). Boletim de Conjuntura, n. 74, set. 2006a.

IPEA (Instituto de Pesquisa Econômica Aplicada). Boletim de Conjuntura, n. 76, mar. 2007.

JONDROW, J.; LOVELL, C. A. K; SCHMIDT, P. On the Estimation of Technical Inefficiency in the Stochastic Frontier Production Model." Journal of Econometrics 19, 233-238, 1982.

KOOPMANS, T. C. An analysis of production as an efficient combination of activities. In: Koopmans, T. C. (Ed.). Activity analysis of production and allocation. Wiley, New York: Cowles Commission for Research in Economics, Monograph, n. 13, 1951.

KNELLER, R.; STEVENS, P. A. The specification of the aggregate production function in the presence of inefficiency. Economic Letters, 81, p. 223-226, 2003.

KOOP, R. J.; DIEWERT, W. E. The decomposition of frontier cost function deviations into measures of technical and allocative efficiency. Journal of Econometrics, v. 19, p. 319 - 331, 1982.

KUMBHAKAR, S. C. Production Frontiers, Panel Data and Time-Varying Technical Inefficiency." Journal of Econometrics 46, 201-211, 1990.

LEE, L. F. A test for Distributional Assumptions for the Stochastic Frontier Functions. J. of Econometrics. 22:245-268, 1983.

MEEUSEN, W.; BROECK, J. Efficiency Estimation from CobbDouglas Production Functions with Composed Error." International Economic Review 18, 435-444, 1997.

NICHOLSON, W. Microeconomic Theory: Basic Principles and Extensions. Canada: Thomson South-Western. Ninth Edition, 2006.
OLIVEIRA-MARTINS, J.; PILAT, D.; SCARPETTA, S. Mark-up ratios in manufacturing industries: Estimates for 14 OECD countries", OECD Economics Department Working Papers, No. 162.

PITT, M. M.; LEE, L. F. Measurement and Sources of Technical Inefficiency in the Indonesian Weaving Industry." Journal of Development Economics 9, 43-64, 1981.

RICHMIND, J. Estimating the Efficiency of Production", International Economic Review, XV (June), 515-21, 1974.

SCHMIDT, P.; LOVELL, C. A. K. Estimating Technical and Allocative Inefficiency Relative to Stochastic Production and Cost Frontiers. Journal of Econometrics, vol. 9, pp. 343-366. NorthHolland, 1979.

SCHMIDT, P.; SICKLES, R. Production Frontiers and Panel Data." Journal of Business E Economic Statistics 2(4), 367-74, 1984.

SEITZ, W. D. Efficiency Measures for Steam-Electric Generating Plants. Proc. Thirty-ninth Ann. Meeting, Western Farm Econ. Assoc, 1966.

SEITZ, W. D. Productive Efficiency in the Steam-Electric Generating Industry," Journal of Political Economy, LXXIX, 878-86, 1971.

SITORUS, B. L. Productive Efficiency and Redundant Factors of Production in Traditional Agriculture of Underdeveloped Countries. Proc. Thirty-ninth Ann. Meeting, Western Farm Econ. Assoc., 1966.

SUMANTH, D. Productivity, Engineering and Management, New York, McGraw-Hill, 1985.

SHEPARD, R. W. Cost and Production Functions, Princeton University Press, 1953.

STEVENSON, R. E. Likelihood Functions for Generalized Stochastic Frontier Estimation. Journal of Econometrics, vol. 13, pp. 57-66. North-Holland, 1980.

TIMMER, C. P. Using a Probabilistic Frontier Production Function to Measure Technical Efficiency, Journal of Political Economy, LXXIX, 776-94, 197 


\section{AUTHOR'S BIOGRAPHY}

Paulo Dutra Costantin received his B.S. in Economics from Universidade Federal de Uberlândia (1993) and completed the Foreign Trade Specialization at Universidade Federal do Rio de Janeiro (1995). He received his master's degree in Economics from Fundação Getulio Vargas - SP (2000), and his PhD in Business Administration at Universidade Presbiteriana Mackenzie (2007). Costantin is a full time Professor in Economics and Advisor for Strategic Planning at Universidade Presbiteriana Mackenzie. His research focuses on Total Factor Productivity (TFP), Vector Error Correction Model (VECM), Cobb-Douglas and Translog Production Function.

Diogenes Manoel Leiva Martin received his B.S. in Business Administration from Fundação Getulio Vargas - SP (1983), a B.S. in Economics from Universidade de São Paulo (1989), and a Bachelor of Law from Pontifícia Universidade Católica de São Paulo (1982). He received his master's degree (1989), and his PhD (1996) in Business Administration from Fundação Getulio Vargas - SP (1996). Martin is a full time Professor in Economics and at the Postgraduate Program in Business Administration at Universidade Presbiteriana Mackenzie (PPGA/Mackenzie). His research focuses on Investment Valuation, Risk Management, Agribusiness, Finance Theory, and Applied Financial Econometrics.

Edward Bernard Bastiaan Rivera Rivera received his B.S. in Business Administration (2006) and a B.S. in Economics (2007) from Universidade Presbiteriana Mackenzie. In 2008, he joined the Postgraduate Program in Business Administration at Universidade Presbiteriana Mackenzie (PPGA/Mackenzie) as a master's student in the Strategic Finance research area, in which he has been awarded a CAPES/PROSUP Type I scholarship. Rivera Rivera's research focuses on Cash Flow at Risk, TFP (DEA, Malmquist, Stochastic Frontier), Comparative Advantages (Balassa, Vollrath, Contribution to the Trade Balance), Resource Based View, Econometrics, Hedonic Prices, Open Macroeconomics, Present Value Model, Unit Root and Cointegration. 